\title{
Illustrations
}

Figures

I.I. Dispositional and situational influences on behavior. $\quad 7$

I.2. A model of social processes in context. IO

2.I. Organizational implications of functional differentiation and social diversity. 26

2.2. The elements of social interaction.

3.I. Shelter satisfaction by shelter. 60

3.2. DMH shelter guests' housing preferences, group and staff.

4.I. Baseline housing preferences. 75

4.2. Clinician housing recommendations and consumer housing preferences. $\quad 76$

4.3. Overall consumer housing preferences and averaged clinician housing recommendations. 77

4.4. Regression analysis: Baseline preference for staffed group home. $\quad 78$

4.5. Baseline shelter satisfaction. $\quad 78$

4.6. Shelter staff project satisfaction after six months. $\quad 79$

4.7. Changes in residential preference. 85

4.8. Regression analysis of preference at eighteen months for staffed group home. 86

4.9. Percentage of days homeless by housing preferred, recommended, and received. 87

5.I. Regression analysis of positive and negative social ties at baseline. $\quad 94$

5.2. Social relations at final assessment. II7

6.I. Lifetime alcohol and drugs at baseline. I25

6.2. Regression analysis of lifetime alcohol abuse at baseline. $\quad I 26$ 


\section{Illustrations $-x$}

6.3. Regression analysis of lifetime drug abuse. $\quad$ I 26

6.4. Lifetime and project alcohol and drug use. $\quad$ I34

6.5. Regression analysis of increased substance use. $\quad$ I35

6.6. Housing loss by lifetime substance abuse. $\quad$ I35

6.7. Housing loss by drug use in project, race, and housing type. $\quad 136$

7.I. Symptoms of depression by SCID diagnosis in baseline interview. $\quad 152$

7.2. Regression analysis of SCID depressive symptoms. $\quad$ I53

7.3. Mean hospitalizations and direct mental health service time by diagnosis. $\quad$ I69

7.4. Mean direct mental health service time by follow-up, diagnosis, and housing type. $\quad I 70$

8.I. Neuropsychological test performance. $\quad$ I $8 I$

8.2. Observed functioning at baseline (LSI scores). $\quad I 82$

8.3. Change in neuropsychological functioning after fifteen months of housing. $\quad 195$

8.4. Executive functioning (WCST Categories Achieved) by ECH-IL by substance abuse. $\quad$ I95

8.5. Regression analysis of change in executive functioning (WCST Categories Achieved). $\quad$ I96

8.6. Regression analysis of change in behavioral turbulence (LSP scale). $\quad 198$

9.I. The empowerment coordinator's diagram of the empowerment concept. 203

9.2. ECH residents advertise for a roommate. 2 I4

IO.I. Percentage of project time spent in different residential circumstances. $\quad 243$

I0.2. Any homelessness during or after the project. 244

I0.3. Percentage of time spent, by location, during and after project. 245

I0.4. Any homelessness by project housing type, by follow-up.

I0.5. Difference in days in shelters between enhanced residential treatment and comparison condition, by substance abuse, in five McKinney projects. $\quad 25 \mathrm{I}$

II.I. Housing satisfaction by housing type by follow-up. $\quad 258$

II.2. Group preference over time. $\quad 267$ 


\section{Illustrations $-x i$}

I I.3. Housing loss if consumers receive housing based on their preference or on clinician recommendation, by housing type received. $27 I$

A.I. Boston McKinney Project research design. $\quad 286$

A.2. Boston McKinney Project housing types. 290

A.3. Project recruitment and attrition. $\quad 309$

\section{Tables}

IO.I. Regression analysis of logged days homeless, in project. $\quad 248$

I0.2. Regression analysis of logged time homeless, post-project. 249

I0.3. Regression analysis of time in independent living/total time housed, post-project. 249

A.r. Boston McKinney Project substance abuse measures and coding. $\quad 298$

A.2. Neuropsychological performance of total sample at baseline compared to normal population. 299

A.3. Boston McKinney project sample characteristics. 3 Iо

A.4. Features of five McKinney projects. 3 I2 
